\title{
Updates in Diagnosis and Treatment of Acromegaly
}

\author{
Roula Zahr ${ }^{1}$ and Maria Fleseriu'1,2,3 \\ 1. Department of Medicine, Division of Endocrinology, Diabetes and Clinical Nutrition; 2. Department of Neurological Surgery; \\ 3. Northwest Pituitary Center, Oregon Health \& Science University, Portland, OR, US
}

DOI: https://doi.org/10.17925/EE.2018.14.2.57

A cromegaly is a rare disease, caused largely by a growth hormone (GH) pituitary adenoma. Incidence is higher than previously thought. Due to increased morbidity and mortality, if not appropriately treated, early diagnosis efforts are essential. Screening is recommended for all patients with clinical features of GH excess. There is increased knowledge that classical diagnostic criteria no longer apply to all, and some patients can have GH excess with normal GH response to glucose. Treatment is multifactorial and personalised therapy is advised.

\section{Keywords}

Acromegaly, growth hormone, pituitary adenoma, somatostatin receptor ligand

Disclosures: Maria Fleseriu has been a principal investigator with research support to Oregon Health \& Science University for clinical research studies with Novartis, Chiasma and Pfizer, and she has been an occasional scientific consultant for Novartis, Pfizer, Ipsen, Ionis and Chiasma. Roula Zahr has no conflict of interest.

Review Process: Double-blind peer review.

Acknowledgements: The authors thank Shirley McCartney PhD for editorial assistance.

Authorship: All named authors meet the International Committee of Medical Journal Editors (ICMJE) criteria for authorship of this manuscript, take responsibility for the integrity of the work as a whole, and have given final approval to the version to be published.

open Access: This article is published under the Creative Commons Attribution Noncommercial License, which permits any non-commercial use, distribution, adaptation and reproduction provided the original author(s) and source are given appropriate credit. (C) The Authors 2018

Received: 16 February 2018

Accepted: 3 May 2018

Citation: European Endocrinology, 2018;14(2):57-61

Corresponding Author: Maria Fleseriu,

Northwest Pituitary Center, Department of

Neurological Surgery, Oregon Health \& Science

University, Mail Code $\mathrm{CH} 8 \mathrm{~N}, 3303$ SW Bond Ave

Portland, OR 97239, US. E: fleseriu@ohsu.edu

Support: No funding was received in

the publication of this article.
Acromegaly is a chronic disorder characterised by growth hormone (GH) hypersecretion, predominantly caused by a pituitary adenoma. ${ }^{1}$ Disease prevalence ranges from 2.8-13.7 cases and annual incidence is between 0.2-1.1 cases/100,000 people; however, real incidence is likely much higher. ${ }^{2,3}$ Average age at diagnosis ranges from $40-50$ years ${ }^{4-6}$ and mean delay in diagnosis is approximately $10-11$ years. More than $95 \%$ of acromegalic cases are secondary to a pituitary adenoma: somatotrophs or GH-producing cells. In $<5 \%$ of cases, acromegaly is related to a hypothalamic or neuroendocrine tumours, which secrete GH-releasing hormone, leading to excess $\mathrm{GH}$. Peripheral GH-secreting tumours are exceedingly rare.

GH stimulates synthesis of insulin-like growth factor 1 (IGF-1) from the liver and systemic tissues. Hypersecretion of GH leads to excess production of IGF-1. IGF-1 mediates most of the phenotypic features and metabolic effects of $\mathrm{GH}$, but $\mathrm{GH}$ excess also has direct detrimental effects. ${ }^{1,7}$ Acromegaly is associated with increased morbidity and mortality, but mortality returns to that of the normal population after appropriate treatment and biochemical normalisation. ${ }^{8,9}$ This review focusses on several recent updates related to acromegaly diagnosis and treatment.

\section{Screening and diagnosis}

Screening is recommended for all patients presenting with clinical features of acromegaly (such as mass tumour effects, systemic effects of GH/IGF-1 excess, cardiovascular and metabolic features, respiratory and bone/joint manifestations and/or other endocrine consequences). However, screening may also be considered in patients with several medical conditions known to be associated with acromegaly such as type 2 diabetes mellitus, carpal tunnel syndrome, debilitating arthritis, hypertension and sleep apnoea. ${ }^{10-12}$ Awareness of these comorbidities is critical for early detection of acromegaly.

Biochemical screening is the first step for an acromegaly diagnosis. Endocrine Society guidelines and experts' consensus recommend using age- and sex-adjusted IGF-1 levels in combination with GH nadir during an oral glucose tolerance test (OGTT) to diagnose and rule out acromegaly.13,14 Measuring serum IGF-1 is usually the initial screening test. Considerable variation in laboratory results for IGF-1 obtained from different assays, ${ }^{15}$ pose a hindrance to diagnosis. For example, these discrepancies may lead to inaccurate exclusion of a diagnosis. This has been reported in up to $30 \%$ of patients in different laboratories. ${ }^{16}$ Given the methodological differences between assays and to establish accurate laboratory results, interpretation reference intervals must be method-specific, adjusted for age and sex, and stratified according to Tanner stages. ${ }^{17}$ Equivocal or elevated IGF-1 levels require further diagnosis confirmation in most patients. An OGTT with 75 $\mathrm{g}$ glucose is considered the gold standard for diagnosing acromegaly. However, similar to IGF-1 assays, the GH assay method can impact the absolute $\mathrm{GH}$ concentration reported by a laboratory. ${ }^{18}$ As a consequence, the assay method may also impact the cut-off for $\mathrm{GH}$ suppression following oral glucose load. ${ }^{19}$ Current widely used cut-offs for GH after OGTT are 1.0 and 0.4 ng/dL. However, these may not be accurate for all commercial assays, and method-specific values for GH cut-offs must be reported when available. . $3,20^{20}$ 
Severe obesity, prolonged fasting and malnutrition reduce IGF-1 levels in patients without acromegaly ${ }^{21,22}$ and may also impact levels in patients with acromegaly. Random $\mathrm{GH}$ level testing is not recommended for diagnosis given the pulsatile nature of secretion. ${ }^{23}$ Stress, physical exercise, acute critical illness and fasting state can cause physiological higher peak in $\mathrm{GH}$ secretion. ${ }^{24-26}$ In pregnancy, homology between $\mathrm{GH}$ and placental $\mathrm{GH}$ makes $\mathrm{GH}$ measurement especially challenging in acromegaly cases..$^{27}$ Chronic renal failure can lead to higher GH but IGF-1 remains unchanged or can even decrease. ${ }^{28}$ Type 2 diabetes and insulin resistance are associated with higher $\mathrm{GH}$ due to impaired suppression by glucose, while chronic hyperglycaemia has shown to be associated with decreased GH release..$^{29} \mathrm{High}$ GH with low IGF-1 can be observed in states of $\mathrm{GH}$ resistance such as systemic inflammation, chronic liver disease, cirrhosis and anorexia nervosa. ${ }^{30-32}$

Biochemical markers, IGF-1 and GH results may be discordant due to their biological and analytical variability, as mentioned above. Patients with clinically active acromegaly and elevated IGF-1 may still have 'suppressible' GH after OGTT using both cut-offs of 1 and $0.4 \mathrm{ng} / \mathrm{dL}$. These discordant findings were observed in $18-45 \%$ of treatment-naïve patients with acromegaly, 33,34 and in $17-35 \%$ of patients with acromegaly after treatment (surgery, radiotherapy and/or medication). ${ }^{35-37}$ Recent studies showed that a large number of patients with acromegaly can have a very different clinical, biochemical and radiological presentation compared with what is considered a 'classical' one. Patients with a typical clinical phenotype and high IGF-1 levels, can have plasma GH in the 'normal' range with glucose-suppressed $\mathrm{GH}<1 \mu \mathrm{g} / \mathrm{L}$ in $~ 50 \%$ and $<0.4 \mu \mathrm{g} / \mathrm{L}$ in as many as $30 \%$ of patients. ${ }^{33,34}$

In summary, the most important update in screening and diagnosis is an increased knowledge and acceptance of the fact that classical diagnostic criteria of acromegaly no longer apply to all patients.

\section{Imaging}

After GH hypersecretion has been confirmed, the next step is determining the source of excess GH. Pituitary magnetic resonance imaging (MRI) is recommended, given $>95 \%$ of acromegaly cases are caused by a pituitary adenoma. ${ }^{1}$ A computed tomography scan can be obtained when MRI is contraindicated or unavailable. ${ }^{13}$

Certain radiologic characteristics have been recently recognised as markers for disease behaviour and predictors of response to therapy. Adenomas that have a hypointense signal on T2-weighted MRI were found in $>50 \%$ of $\mathrm{GH}$-secreting tumours, to be smaller and less frequently invasive, although associated with higher levels of GH hypersecretion. ${ }^{38}$ IGF-1 decreased by more than half from pre-treatment levels in 66\% of T-2 hypointense versus 31\% of T2-hyperintense adenomas after 6 months of adjunctive somatostatin receptor ligand (SRL) therapy, and normalised in $71 \%$ versus $20 \%$, at 6 months, respectively. ${ }^{39}$

Patients with T2-hypointense adenomas had GH and IGF-1 reductions of $88 \%$ and $59 \%$, respectively after 6 months of pre-surgical SRL treatment, significantly greater than the decreased levels observed with T2-isointense and hyperintense tumours. Tumour shrinkage was also greater in T2-hypointense tumours. Lower T2-signal intensity was found to correlate with a better hormonal response, but the correlation with tumour shrinkage was inconsistent among studies. ${ }^{40-42}$

\section{Pathology}

In 2017, the World Health Organization updated the histological grading of pituitary neuroendocrine tumours. ${ }^{43}$ The new grading abandoned the term 'atypical adenoma' and emphasised the evaluation of morphology, tumour proliferation and invasion status for prognostication and evaluation of aggressiveness. ${ }^{44}$

GH-producing pituitary adenomas have several histological subtypes, and differ in morphology, clinical and biological behaviour. Classification is derived from the results of hematoxylin-eosin stain, immunohistochemistry, appearance under an electron microscope and transcription factors expressed in cells, and the following subtypes are established:

\section{- $\quad$ GH-producing adenomas:}

densely granulated somatotroph adenomas (DGSA)

sparsely granulated somatotroph adenomas (SGSA); and intermediate granulated somatotroph adenomas.

- $\quad$ mixed $\mathrm{GH} /$ prolactin producing adenomas: mammosomatotroph adenomas; and acidophil stem cell adenoma.

- $\quad$ plurihormonal adenomas, and silent somatotroph adenomas. ${ }^{45}$

DGSA are found in $40 \%$ of acromegaly tumours, while SGSA are found in $30 \%{ }^{46,47}$ SGSA are usually larger at diagnosis than DGSA (21.6 mm versus $19.2 \mathrm{~mm}$, respectively), have lower somatostatin receptor subtype 2 positivity (50\% versus 100\%) and higher Ki-67 proliferation index (>3\% in $67 \%$ of SGSAs versus $<3 \%$ in $89 \%$ in DGSA). ${ }^{48}$ Sparse granulation pattern has been also correlated with adenoma hyperintensity signal on T2-weighted MRI. ${ }^{49}$

Patients with SGSA usually require more surgeries, more radiotherapy, multiple different medications, a higher number of combined treatments and show medication resistance more often than DGSA. In a recent large study, median time for biochemically controlled acromegaly, using age-adjusted IGF-1 levels, was 9.7 years versus 16 years, in SGSA and DGSA, respectively. ${ }^{50}$

Intermediate granulated somatotroph adenomas have similar clinical behaviour to DGSA. Both acidophil stem cell and plurihormonal adenomas have been associated with aggressive behaviour, while clinical behaviour of silent somatotroph adenomas is variable, but often aggressive. ${ }^{.51-53} \mathrm{It}$ is essential that pathology defines the exact type of GH pituitary adenoma in all patients undergoing surgery, as it has been proven to predict both clinical and biochemical outcomes.

\section{Treatment}

Transsphenoidal pituitary adenoma resection is generally the first-line therapy. Successful surgery provides immediate reduction of GH levels and provides tumour tissue for diagnostic and prognostic purposes. ${ }^{13}$ However, not all patients achieve remission after surgery and acromegaly treatment is frequently multimodal..$^{54}$

When operated on by an experienced pituitary surgeon, the outcome of transsphenoidal surgery for acromegaly is similar to endoscopic and microscopic techniques. Highly experienced pituitary centres, lower preoperative GH level, small size of tumour, and extrapseudocapsular resection are factors associated with higher remission rates postoperatively, while lower remission rate is seen with macroadenomas and tumours invading the carvernous sinus and parasellar area. GH values $<1 \mathrm{ng} / \mathrm{mL}$ within the first 72 hours after surgery is a positive predictive factor for remission. ${ }^{44-56}$

Pharmacologic agents available for treatment of acromegaly include somatostatin-receptor ligands, GH-receptor antagonists and, in selected 
Table 1: Acromegaly medical therapy

\begin{tabular}{|c|c|c|c|c|c|}
\hline Variable & Route & Usual dose & Dose schedule & Possible side effects & Efficacy (approx) \\
\hline \multicolumn{6}{|l|}{ Centrally acting agents } \\
\hline Octreotide & SC & 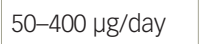 & 1-4 times/day & \multirow{3}{*}{$\begin{array}{l}\text { nausea, vomiting, diarrhoea, constipation, } \\
\text { abdominal pain, cholelithiasis/biliary sludge, } \\
\text { bloating, bradycardia, fatigue, headache, } \\
\text { alopecia, dysglycaemia }\end{array}$} & \multirow{3}{*}{$\begin{array}{l}30-60 \% \\
\text { (depending on primary } \\
\text { versus. adjuvant therapy, } \\
\text { composite endpoint and dose } \\
\text { escalation) }\end{array}$} \\
\hline Octreotide LAR & $\mathrm{IM}$ & $20-40 \mathrm{mg}$ & Monthly & & \\
\hline Lanreotide & deep SC & $60-120 \mathrm{mg}$ & $\begin{array}{l}\text { Monthly } \\
\text { (4-6 weeks) }\end{array}$ & & \\
\hline Pasireotide LAR & $\mathrm{IM}$ & 40-60 mg & Monthly & Same as above, with more hyperglycaemia & $40 \%$ \\
\hline Cabergoline & Oral & $1-4 \mathrm{mg}$ & Bi-weekly up to daily & Nausea, dizziness, orthostatic hypotension & $30-40 \%$ in mild acromegaly \\
\hline $\begin{array}{l}\text { Oral octreotide } \\
\text { (in development, } \\
\text { phase III clinical trials) }\end{array}$ & Oral & $40-80 \mathrm{mg}$ & 2 times/day & $\begin{array}{l}\text { nausea, vomiting, diarrhoea, dyspepsia, } \\
\text { cholelithiasis, headaches, dizziness, } \\
\text { dysglycaemia }\end{array}$ & $65 \%$ \\
\hline \multicolumn{6}{|l|}{ GH receptor blocker } \\
\hline Pegvisomant & SC & 10-40 mg & Daily & $\begin{array}{l}\text { Transaminases elevation, lipodystrophy, } \\
\text { arthralgias }\end{array}$ & 60-90\% \\
\hline \multicolumn{6}{|l|}{ Combination therapy } \\
\hline $\begin{array}{l}\text { Pegvisomant-SRL } \\
\text { (Octreotide or Lanreotide) }\end{array}$ & & $\begin{array}{l}\text { PEG 25-160 mg/ } \\
\text { week } \\
\text { LAN } 120 \mathrm{mg} \\
\text { OCT } 30 \mathrm{mg}\end{array}$ & $\begin{array}{l}\text { Daily to Weekly } \\
\text { Monthly } \\
\text { Monthly }\end{array}$ & & $62-100 \%$ \\
\hline Pegvisomant-pasireotide LAR & & $\begin{array}{l}\text { PEG 21-78 mg } \\
\text { PAS } 60 \mathrm{mg}\end{array}$ & $\begin{array}{l}\text { Weekly } \\
\text { Monthly }\end{array}$ & & $68 \%$ \\
\hline $\begin{array}{l}\text { Cabergoline-SRL } \\
\text { (Octreotide or Lanreotide) }\end{array}$ & & $\begin{array}{l}\text { CAB 1-3.5 mg/ } \\
\text { week } \\
\text { OCT } 30 \mathrm{mg} \\
\text { LAN 60-90 mg }\end{array}$ & $\begin{array}{l}\text { Bi-weekly } \\
\text { Monthly } \\
\text { Monthly }\end{array}$ & & $30-56 \%$ \\
\hline Cabergoline-pegvisomant & & $\begin{array}{l}\text { CAB 1-3.5 mg/ } \\
\text { week } \\
\text { PEG 10-30 mg/ } \\
\text { day }\end{array}$ & $\begin{array}{l}\text { Bi-weekly } \\
\text { Daily }\end{array}$ & & $13-28 \%$ \\
\hline
\end{tabular}

$C A B=$ cabergoline; $G H=$ growth hormone; $I M=$ intramuscular $;$ LAN = lanreotide; $L A R=$ long-acting release; $O C T=$ octreotide; $P A S=$ pasireotide; $P E G=$ pegvisomant; $S C=$ subcutaneous; $S R L=$ somatostatin receptor ligand. Adapted from Langlois et al, 2017.57

cases, dopamine agonists (Table 1). ${ }^{57}$ The first-generation of SRLS, octreotide and lanreotide, have been the mainstay of medical treatment, ${ }^{1}$ however, most recently pegvisomant (a genetically engineered, recombinant $\mathrm{GH}$-receptor antagonist) has also been used as a first-line treatment. ${ }^{58,59}$ Biochemical response and tumour reduction with SRLs varies widely between studies, from $20-70 \%$, depending on the study design, history of surgical debulking and endpoint of the study itself (IGF-1, GH or composite GH and IGF-1). In a recent meta-analysis evaluating the effect of study design on the reported biochemical response rates to SRL, overall efficacy response rate was $56 \%$ for $\mathrm{GH}$ control and 55\% for IGF-1 normalisation, without significant difference between SRL types..$^{60}$ However, efficacy was only approximately $40 \%$ for GH normalisation in treatment-naïve, newly diagnosed patients treated with lanreotide autogel. .11,62 $^{\text {Tumour volume reduction of }>20 \% \text { was }}$ found in $75 \%$ and $54.1 \%$ of patients treated with octreotide long-acting release (LAR) and lanreotide autogel, respectively, but with different duration of follow-up. ${ }^{22-64}$

Symptoms and quality of life (QoL) were recently evaluated in a 1-year, open-label study of lanreotide autogel in acromegaly treatmentnaive patients. Symptoms improved in 60\% using a Patient-assessed
Acromegaly Symptom Questionnaire, while 40\% had improved healthrelated QoL using the AcroQoL questionnaire. Clinical symptoms improved in both patients with and without biochemically controlled disease. ${ }^{65}$ However, a cross-sectional study comparing QoL between patients with treated and controlled acromegaly and healthy controls, and a longitudinal study assessing QoL changes in patients with biochemically stable disease during approximately 6 years of follow-up demonstrated that impaired QoL in patients with acromegaly persisted despite longterm disease control. Notably, duration of disease control and present use of medical therapy for acromegaly influence QoL the most. ${ }^{66}$

In patients resistant to first-generation SRLS, alternative options are high-dose regimens of SRL, pegvisomant, combination therapy of SRL with either cabergoline or pegvisomant, or the use of pasireotide. ${ }^{67}$ Pasireotide is a next-generation SRL recently approved for the treatment of acromegaly not cured by surgery or when surgery is not an option. As a first-line therapy, pasireotide LAR resulted in higher rates of hormonal control and tumour size reduction compared to octreotide LAR. ${ }^{68}$ In 130 patients resistant to first-generation SRL randomised to pasireotide LAR $40 \mathrm{mg}$ or $60 \mathrm{mg}$, a complete biochemical response was achieved in 15\% and $20 \%$, respectively. ${ }^{69}$ The safety profile is similar to first-generation 
SRLS, except for hyperglycaemia, which occurred more frequently and more severely with pasireotide. .670 The frequency of hyperglycaemia was similar in responders and non-responders to pasireotide. Baseline glucose status (fasting levels $>100 \mathrm{mg} / \mathrm{dL}$ ) is a potential predictive factor to higher glucose and haemoglobin $\mathrm{A} 1 \mathrm{C}$ after treatment. ${ }^{71}$ The reduction in insulin and incretin hormones secretion are thought to be contributors, but the exact mechanisms are not completely understood $d^{72,73}$ and further studies are ongoing.

Pegvisomant is a US Food and Drug Administration-approved treatment for use after surgery. In a global non-interventional safety surveillance study, pegvistomant normalised IGF-1 in $67.5 \%$ of patients after 5 years (most likely due to lack of dose-up titration), and also improved clinical

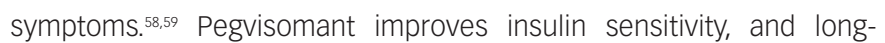
term follow-up showed significantly decreased fasting glucose over time, while first-generation SRL only have a marginal clinical impact on glucose homeostasis in acromegaly. ${ }^{74,75}$ Pegvisomant does not have any direct anti-proliferative effects on pituitary tumour cells, but tumour growth is rare overall. In clinical trials of patients treated with pegvisomant and with available MRI the incidence of increase in pituitary tumor size was $3.2 \% .^{58,59}$

Cabergoline has been recommended by guidelines and consensus meetings to be considered in patients uncontrolled on SRL monotherapy who have baseline IGF-1 levels up to 1.5-2.2 times above the upper limit of normal. ${ }^{13,14}$ Adding cabergoline to ongoing SRL therapy has been reported to achieve IGF-1 normalisation in $30-56 \%$ of patients who had uncontrolled acromegaly on SRL-monotherapy. $67,7,7,77$

Patients with a higher degree of resistance to SRL monotherapy should be considered for combined SRL-pegvisomant ${ }^{13,14}$ or pasireotide treatment. ${ }^{67}$ Combined therapy of SRL and pegvisomant in patients with uncontrolled disease on SRL had a high rate of efficacy in different studies, 62-100\%, in both primary and adjuvant therapy.77,78 Differences in reported outcomes are likely related to many factors including heterogeneity in study designs such as IGF-1 assays, inclusion/exclusion criteria, and inconsistent medications dosing and titration protocols. Another factor is the different IGF-1 criteria used to define efficacy, with some studies using the lowest achieved IGF-1 level at any point versus the level at the end of study in others. Switching 61 patients with well-controlled disease on a combined therapy of pegvisomant-first-generation SRL to pasireotide LAR resulted in a $66 \%$ reduction in pegvisomant dose, while $67 \%$ of patients could discontinue pegvisomant at 24 weeks..$^{79}$ All combination treatment therapies have potentially higher rates of adverse events than single treatment therapy, and therefore patients require close monitoring.

There are several new therapies in development, including new delivery systems, ${ }^{80}$ or extended interval (lanreotide prolonged release formulation). ${ }^{81}$ Oral octreotide, an oral therapeutic peptide has shown efficacy in a large phase III trial in controlling IGF-1 and GH after switching from injectable SRLs in 65\% of patients for up to 13 months, with a safety profile consistent with other SRLS. ${ }^{82}$ Primary surgical debulking has been shown in a recent study to be superior to primary medical therapy for macroadenoma, with a $50 \%$ and $6.7 \%$ response rate, respectively. The response rate remains highest when medical therapy is added after surgical failure at $77 \% .^{83}$

The impact of pre-operative SRL therapy on peri-operative and long-term outcome is not clear. Although improvement in short-term remission rate was reported for macroadenomas and invasive adenomas, there was no significant change in the long term. No favourable effect on cardiac function, anaesthetic risks, surgical outcome or hospital outcome has yet been demonstrated, however selected cases might benefit clinically. ${ }^{84-87}$

Radiation therapy remains third in line in the treatment algorithm for acromegaly, and is usually considered in cases of large residual (or enlarging) tumour following surgery, and if medical therapy is unsuccessful or not tolerated. ${ }^{13}$ Stereotactic techniques, stereotactic radiosurgery (SRS) and fractionated stereotactic radiotherapy (FSRT) provide more precise, higher radiation dose to the targeted tumour, and limit irradiation to the adjacent normal structures compared to conventional radiotherapy (CRT). In a recent systematic review, the efficacy of SRS was similar to CRT, but has a potentially higher rate of biochemical control and lower rate of hypopituitarism..$^{88}$ Favourable prognostic factors for efficacy of SRS include a higher margin radiation, higher maximum dose and lower initial GH/IGF-1 levels. ${ }^{89}$ The main side effect of SRS is radiationinduced hypopituitarism, while optic neuropathy, cranial neuropathies, brain radionecrosis and cerebrovascular disease occurred infrequently. ${ }^{90}$ FSRT appears to have a similar efficacy and risks with SRS except for the stroke risk that seems to be higher with FSRT.90,91

\section{Conclusion}

Novel insights into the diagnosis and pathophysiology of acromegaly have been acquired over recent years. Increased awareness of assay technical issues and discordant results affecting the biochemical assessment of the disease will ensure prompt diagnosis and initiation of treatment. Expanded knowledge on the histological and molecular levels, and development of new markers of response and resistance to SRL emphasised the importance of a personalised approach rather than following a universal algorithm for therapy. Future studies are needed to clarify the role of innovative formulation, combination and perioperative pharmacotherapy on disease remission rate and patient QoL. The treatment of acromegaly remains multimodal for most patients and a multidisciplinary team is essential for optimal disease management and outcome. $\square$
1. Melmed $\mathrm{S}$, Acromegaly pathogenesis and treatment. J Clin Invest. 2009:119:3189-202.

2. Daly AF, et al. High prevalence of pituitary adenomas: a cross-sectional study in the province of Liege, Belgium. I Clin Endocrinal Metab. 2006;91;4769-75.

3. Fernandez A, Karavitaki N Wass JA. Prevalence of pituitary adenomas: a community-based, cross-sectional study in Banbury (Oxfordshire, UK). Clin Endocrinol (OXf). 2010;72;377-82.

4. Burton $\mathrm{T}$, et al. Incidence and prevalence of acromegaly in a large US health plan database. Pituitary. 2016;19;262-7.

Capatina C, Wass JA. 60 years of neuroendocrinology: acromegaly. J Endocrinol. 2015;226:T141-60.

Reid TJ et al. Features at diagnosis of 324 patients with acromegaly did not change from 1981 to 2006: acromegaly remains under-recognized and under-diagnosed. Clin Endocrinol (Oxf). 2010;72:203-8.

Vilar L et al. Acromegaly: clinical features at diagnosis. Pituitary, 2017;20:22-32.

8. Dekkers $\mathrm{OM}$ et al. Mortality in acromegaly: a metaanalysis J Clin Endocrinol Metab. 2008;93:61-7.
9. Holdaway IM, Bolland MJ, Gamble GD. A meta-analysis of the effect of lowering serum levels of $\mathrm{GH}$ and IGF-I on mortality in acromegaly. Eur J Endocrinol. IGF-I on mortality in

10. Sesmilo $G$, et al. Prevalence of acromegaly in patients with symptoms of sleep apnea. PLoS One. 2017;12:e0183539.

11. Rosario PW Frequency of acromegaly in adults with diabetes or glucose intolerance and estimated prevalence in the general population. Pituitary. 2011;14:217-21.

12. Molitch ME. Clinical manifestations of acromegaly. Endocrinol Metab Clin North Am. 1992;21:597-614.

13. Katznelson $\mathrm{L}$, et al. Acromegaly: an endocrine society clinical practice guideline. J Clin Endocrinol Metab. 2014;99:3933-51.

14. Melmed $\mathrm{S}$, et al. A consensus on the diagnosis and treatment of acromegaly complications. Pituitary. 2013;16:294-302.

15. Frystyk J, Freda P, Clemmons DR. The current status of IGF-I assays - a 2009 update. Growth Horm IGF Res. 2010:20:8-18. 16. Pokrajac A, et al. Variation in GH and IGF-I assays limits the applicability of international consensus criteria to local practice.
Clin Endocrinol (0xf) 2007:67:65-70.

17. Bidlingmaier $M$, et al. Reference intervals for insulin-like growth factor-1 (igf-i) from birth to senescence: results from a multicenter study using a new automated chemiluminescence IGF-I immunoassay conforming to recent international recommendations. J Clin Endocrinol Metab. 2014;99:1712-21.

18. Clemmons DR. Consensus statement on the standardization and evaluation of growth hormone and insulin-like growth factor assays. Clin Chem. 2011;57:555-9.

19. Arafat $\mathrm{AM}$, et al. Growth hormone response during oral glucose tolerance test: the impact of assay method on the estimation of reference values in patients with acromegaly and in healthy controls, and the role of gender, age, and body mass index J Clin Endocrinol Metab. 2008;93:1254-62.

20. Giustina A, et al. A consensus on criteria for cure of acromegaly. J Clin Endocrinol Metab. 2010;95:3141-8.

21. Brick DJ, et al. Determinants of IGF1 and GH across the weight spectrum: from anorexia nervosa to obesity. Eur J Endocrinol. 2010;163:185-91.

22. Smith WJ, Underwood LE, Clemmons DR. Effects of caloric or 
protein restriction on insulin-like growth factor-I (IGF-I) and IGF-binding proteins in children and adults. J Clin Endocrinol Metab 1995:80:443-9.

23. Hartman ML, Veldhuis JD, Thorner MO. Normal control of growth hormone secretion. Horm Res 1993:40:37-47.

24. Gunawardane $K$, et al. Normal Physiology of Growth Hormone in Adults. In De Groot $\sqcup$ et al. (eds). Endotext. MDText.com; South Dartmouth (MA). 2000.

25. Wideman $\mathrm{L}$, et al. Growth hormone release during acute and chronic aerobic and resistance exercise: recent findings Sports Med. 2002;32:987-1004

26. Elijah IE, et al. The GH/IGF-1 system in critical illness. Best Pract Res Clin Endocrinol Metab. 2011;25:759-67.

27. Muhammad A, Neggers SJ, van der Lely AJ, Pregnancy and acromegaly. Pituitary,. 2017;20:179-184.

28. Rabkin R. Growth factor insensitivity in renal failure. Ren Fail. 2001;23:291-300

29. Anderwald $\mathrm{CH}$, et al. Whole-body insulin sensitivity rather than body-mass-index determines fasting and post-glucose-load growth hormone concentrations. PLOS One. 2014:9:e115184.

30. Brambilla F, et al. Growth hormone and insulin-like growth factor 1 secretions in eating disorders: correlations with psychopathological aspects of the disorders Psychiatry Res. 2017;263:233-237.

31. DeBoer MD, et al. Systemic inflammation, growth factors, and linear growth in the setting of infection and malnutrition. Nutrition. 2017:33:248-53.

32. Donaghy $A$, et al. Growth hormone, insulinlike growth factor-1, and insulinlike growth factor binding proteins 1 and 3 in chronic liver disease. Hepatology. 1995;21:680-8.

33. Butz LB, et al. 'Micromegaly': an update on the prevalence of acromegaly with apparently normal GH secretion in the modern era Pituitary 2016:19:547-51.

34. Freda PU, et al. Basal and glucose-suppressed GH levels less than $1 \mathrm{microg} / \mathrm{L}$ in newly diagnosed acromegaly. Pituitary. 2003;6:175-80.

35. Carmichael JD, et al. The utility of oral glucose tolerance testing for diagnosis and assessment of treatment outcomes in 166 patients with acromegaly. I Clin Endocrinol Metab. 2009;94: 523-7.

36. Elias PC, et al. Discordant nadir GH after oral glucose and IGF-I levels on treated acromegaly: refining the biochemical markers of mild disease activity. Horm Metab Res. 2010;42:50-5.

37. Sherlock $\mathrm{M}$, et al. Monitoring disease activity using GH and IGF-I in the follow-up of 501 patients with acromegaly. Clin Endocrinol (Oxf). 2009;71:74-81.

38. Potorac I, et al. Pituitary MRI characteristics in 297 acromegaly patients based on T2-weighted sequences. Endocr Relat Cancer, 2015;22:169-77.

39. Puig-Domingo $\mathrm{M}$, et al. Magnetic resonance imaging as a predictor of response to somatostatin analogs in acromegaly after surgical failure. J Clin Endocrinol Metab. 2010;95:4973-8.

40. Potorac I, et al. T2-weighted MRI signal predicts hormone and tumor responses to somatostatin analogs in acromegaly. Endocr Relat Cancer. 2016;23:871-81.

41. Heck A, et al. Quantitative analyses of T2-weighted MRI as a potential marker for response to somatostatin analogs in newly diagnosed acromegaly. Endocrine. 2016;52:333-43.

42. Shen $\mathrm{M}$, et al. Predictive value of $\mathrm{T} 2$ relative signal intensity for response to somatostatin analogs in newly diagnosed acromegaly. Neuroradiology. 2016;58:1057-65.

43. Lloyd R, Osamura R, Klöppel G, Rosai J. WHO Classification of Tumours of Endocrine Organs. Fourth edition, volume 10 (IARC Publications: Lyon, France, 2017).

44. Lopes MBS. The 2017 World Health Organization classification of tumors of the pituitary gland: a summary. Acta Neuropathol. 2017:134:521-35.

45. Syro LV, et al. Pathology of $\mathrm{GH}$-producing pituitary adenomas and GH cell hyperplasia of the pituitary. Pituitary. 2017;20:84-92.

46. Lopes MB, Growth hormone-secreting adenomas: pathology and cell biology. Neurosurg Focus. 2010;29:E2

4. Horvath E, Kovacs K, Pathology of acromegaly. Neuroendocrinology. 2006;83:161-5.
48. Brzana J, et al. Growth hormone granulation pattern and somatostatin receptor subtype $2 \mathrm{~A}$ correlate with postoperative somatostatin receptor ligand response in acromegaly: a large single center experience. Pituitary. 2013:16:490-8.

49. Heck A. et al. Intensity of pituitary adenoma on T2-weighted magnetic resonance imaging predicts the response to octreotide treatment in newly diagnosed acromegaly. Clin Endocrinol (OXf). 2012;77:72-8.

50. Cuevas-Ramos D, et al. A structural and functional acromegaly classification. J Clin Endocrinol Metab. 2015;100:122-31.

51. Mete O,Asa SL, Clinicopathological correlations in pituitary adenomas. Brain Pathol. 2012;22:443-53.

52. Erickson D, et al. Silent subtype 3 pituitary adenoma: a clinicopathologic analysis of the Mayo Clinic experience. Clin Endocrinol (OXf). 2009;71:92-9.

53. Chinezu L, et al. Silent GH pituitary tumour: diagnostic and therapeutic challenges. Ann Endocrinol (Paris). 2013;74:491-5.

54. Starke RM, et al. Endoscopic vs microsurgical transsphenoidal surgery for acromegaly: outcomes in a concurrent series of patients using modern criteria for remission. I Clin Endocrino Metab. 2013:98:3190-8.

55. Anik I, et al. Endoscopic transsphenoidal approach for acromegaly with remission rates in 401 patients: 2010 consensus criteria. World Neurosurg. 2017;108:278-90.

56. Schofl $\mathrm{C}$, et al. Long-term outcome in patients with acromegaly: analysis of 1344 patients from the German Acromegaly Register. Eur J Endocrinol. 2013;168:39-47.

57. Langlois F, McCartney S, Fleseriu M, Recent progress in the medical therapy of pituitary tumours. Endocrinol Metab (Seoul). 2017:32:162-70.

58. Tritos NA, et al. Effectiveness of first-line pegvisoman monotherapy in acromegaly: an ACROSTUDY analysis. Eur J Endocrinol. 2017:176:213-20.

59. van der Lely AJ, et al. Long-term safety of pegvisomant in patients with acromegaly: comprehensive review of 1288 subjects in ACROSTUDY. J Clin Endocrinol Metab. 2012;97:1589-97.

60. Carmichael JD, et al. Acromegaly clinical trial methodology impact on reported biochemical efficacy rates of somatostatin receptor ligand treatments: a meta-analysis. I Clin Endocrinol Metab. 2014;99:1825-33.

61. Annamalai AK, et al. A comprehensive study of clinica, biochemical, radiological, vascular, cardiac, and sleep parameters in an unselected cohort of patients with acromegaly undergoing presurgical somatostatin receptor ligand therapy. J Clin Endocrinol Metab. 2013;98:1040-50.

62. Caron PJ, et al. Tumor shrinkage with lanreotide Autoge $120 \mathrm{mg}$ as primary therapy in acromegaly: results of a prospective multicenter clinical trial. J Clin Endocrinol Metab. 2014:99:1282-90.

63. Mercado $\mathrm{M}$, et al. A prospective, multicentre study to investigate the efficacy, safety and tolerability of octreotide LAR (long-acting repeatable octreotide) in the primary therapy of patients with acromegaly. Clin Endocrinol (OXf). 2007;66:859-68

64. Giustina A, et al. Meta-analysis on the effects of octreotide on tumor mass in acromegaly. PLOS One, 2012;7:e36411.

65. Caron PJ, et al. Effects of lanreotide Autogel primary therapy on symptoms and quality-of-life in acromegaly: data from the PRIMARYS study. Pituitary. 2016;19:149-57.

66. Kyriakakis $\mathrm{N}$, et al. Impaired quality of life in patients with treated acromegaly despite long-term biochemically stable disease: results from a 5-years prospective study. Clin Endocrinol (OXf). 2017;86:806-15.

67. Lim DS, Fleseriu M, The role of combination medical therapy in the treatment of acromegaly. Pituitary. 2017:20:136-48.

68. Colao A, et al. Pasireotide versus octreotide in acromegaly: a head-to-head superiority study. J Clin Endocrinol Metab. 2014:99:791-9.

69. Gadelha MR, et al. Pasireotide versus continued treatment with octreotide or lanreotide in patients with inadequately controlled acromegaly (PAOLA): a randomised, phase 3 tria. Lancet Diabetes Endocrinol. 2014;2:875-84.
70. Fleseriu M, et al. Safety and tolerability of pasireotide longacting release in acromegaly-results from the acromegaly, open-label, multicenter, safety monitoring program for treating patients who have a need to receive medical therapy (ACCESS) study. Endocrine. 2017;55:247-55.

71. Schmid HA, et al. Effect of pasireotide on glucose- and growth hormone-related biomarkers in patients with inadequatel controlled acromegaly. Endocrine. 2016;53:210-9.

72. Henry RR, et al. Hyperglycemia associated with pasireotide: results from a mechanistic study in healthy volunteers. J Clin Endocrinol Metab. 2013;98:3446-53.

73. Breitschaft A, et al. Management of hyperglycemia associated with pasireotide (SOM230): healthy volunteer study. Diabetes Res Clin Pract. 2014;103:458-65.

74. Chanson P, et al. Pegvisomant treatment in patients with acromegaly in clinical practice: the French ACROSTUDY. Ann Endocrinol (Paris). 2015;76:664-70.

75. Mazziotti $\mathrm{G}$, et al. Effects of somatostatin analogs on glucose homeostasis: a metaanalysis of acromegaly studies. J Clin Endocrinol Metab. 2009:94:1500-8.

76. Suda K, et al. Efficacy of combined octreotide and cabergoline treatment in patients with acromegaly: a retrospective clinic study and review of the literature. Endocr J. 2013;60:507-15.

77. Puig-Domingo $\mathrm{M}$, et al. Use of lanreotide in combination with cabergoline or pegvisomant in patients with acromegaly in the clinical practice: the ACROCOMB study. Endocrinol Nutr. 2016;63:397-408

78. Neggers $\mathrm{SJ}$, et al. Long-term efficacy and safety of pegvisomant in combination with long-acting somatostatin analogs in acromegaly. J Clin Endocrinol Metab. 2014;99:3644-52.

79. Muhammad A, et al. Efficacy and safety of switching to pasireotide in patients with acromegaly controlled with pegvisomant and first-generation somatostatin analogues PAPE Study I Clin Endocrinol Meta. 2018:103:586-95.

Melmed S, New therapeutic agents for acromegaly. Nat Rev Endocrinol. 2016;12:90-8.

81. ClinicalTrials.gov, Study to Determine the Maximum Tolerated Dose, Safety and Tolerability of a Single Dose of Lanreotide Prolonged Release Formulation (PRF) in Subjects With Acromegaly. ClinicalTrials.gov, 2017

82. Melmed S, et al. Safety and efficacy of oral octreotide in acromegaly: results of a multicenter phase III trial. J Cli Endocrinol Metab. 2015;100:1699-708.

83. Fahlbusch $\mathrm{R}$, et al. Surgical debulking of pituitary adenomas improves responsiveness to octreotide lar in the treatment of acromegaly. Pituitary. 2017;20:668-75.

84. Fleseriu M, et al. American Association of Clinical Endocrinologists and American College of Endocrinology Disease State Clinical Review: Management of acromegaly patients: what is the role of pre-operative medical therapy? Endocr Pract. 2015:21:668-73.

85. Li ZQ et al. Preoperative lanreotide treatment improves outcome in patients with acromegaly resulting from invasive pituitary macroadenoma. I Int Med Res. 2012;40:517-24.

86. Mao ZG, et al. Preoperative lanreotide treatment in acromegalic patients with macroadenomas increases short-term postoperative cure rates: a prospective, randomised trial. Eur J Endocrinol. 2010;162:661-6.

87. Zhang $\mathrm{L}$, et al. Preoperative somatostatin analogs treatment in acromegalic patients with macroadenomas. A meta-analysis. Brain Dev. 2015;37:181-90.

88. Abu Dabrh AM, et al. Radiotherapy versus radiosurgery in treating patients with acromegaly: a systematic review and meta-analysis. Endocr Pract. 2015;21:943-56.

89. Lee CC, et al. Stereotactic radiosurgery for acromegaly. J Clin Endocrinol Metab. 2014; 99:1273-81.

90. Gheorghiu ML, Updates in outcomes of stereotactic radiation therapy in acromegaly. Pituitary. 2017;20:154-68.

91. Patt $H$ et al. High-precision conformal fractionated radiotherapy is effective in achieving remission in patients with acromegaly after failed transsphenoidal surgery. Endocr Pract. 2016;22:162-72 